7th International Conference on Mobile Business

\title{
Knowledge-based Bundling of Smart Products on a Mobile Recommendation Agent
}

\author{
Tobias Kowatsch, Wolfgang Maass, Andreas Filler \& Sabine Janzen \\ Hochschule Furtwangen University, Robert-Gerwig-Platz 1, 78120 Furtwangen, Germany \\ \{tobias.kowatsch,wolfgang.maass, andreas.filler, sabine.janzen\}@hs-furtwangen.de
}

\begin{abstract}
Mobile technologies have the potential to change not only brick-and-mortar stores but also the way, how customers interact with physical products. They enable operational agility by means of improved availability and quality of information required by customers for in-store purchase decisions. In this paper, we show how an in-store bundling scenario can be supported by semantically enriched products (denoted as smart products) that provide dynamic product information through the use of mobile recommendation agents (MRA). We introduce therefore the concept of knowledge-based bundling that relies on smart products and MRA. In addition, we developed a MRA and evaluated its user acceptance for product bundle purchases. For this purpose, a lab experiment was conducted ( $n=37)$, which resulted in some design enhancements and promising adoption rates.
\end{abstract}

\section{Introduction}

Mobile technologies in brick-and-mortar stores are able to revolutionize the interaction between customers, retailers and producers as they enable operational agility by means of improved availability and quality of information [1]. Increasingly, online recommendation agents help customers to make educated buying decisions, to better understand customer needs but also to exert influence [2]. At the same time, products embed information technology that allows the differentiation of products in competitive markets [3]. This kind of technologies will rapidly change the design of products and their business models. Step by step, products will become interactive, adaptive to contexts and users, and business-aware, i.e., products will gain capabilities to sell themselves or to bundle with other products in mobile shopping environments.
For the realization of this vision of ambient intelligence, wireless information and communication technologies have to be embedded into any kind of physical product, a basic infrastructure must be available that enables communication between these products and finally the customer requires an adequate interface for interaction. The concept of smart products is one step towards this vision [4].

Smart products can be identified by mobile recommendation agents (MRA) - e.g. through RFID technology - and provide customers with dynamic product information that also include information of related or compatible products $[5,6]$. Therefore, they support customers in their buying decisions. From the retailer's perspective, smart products can also be used to implement several forms of price discrimination [7], which can be manipulated on demand and thus improve the agility of bricks-and-mortar stores. In particular, bundling strategies allow retailers to reduce their costs and at the same to skim consumer surplus [8]. Correspondingly, smart products would improve the retailer's agility as the composition of product bundles can be defined on demand, e.g. by considering the store's inventory [9] or based on strategic objectives or technical compatibility [10].

In this paper, we show how an in-store bundling scenario can be supported by smart products that provide dynamic product information through the use of MRA. For this purpose, we introduce the concept of knowledge-based bundling that relies on smart products and MRA. In particular, we define product bundles by SWRL rules using the Smart Product Description Object (SPDO) [4] and show how MRA are used to find product bundles. In addition, we developed a MRA running on an RFID-enabled PDA and evaluated its user acceptance for product bundle purchases by conducting a lab experiment $(n=37)$.

Hence, our research adopts a design science methodology and fully applies a build-and-evaluate loop as proposed by Hevner et al. [11]. First, we 
reviewed literature on smart products, bundling and MRA (Section 2) before we identified a business need in the form of a bundling scenario based upon smart products and MRA as they improve operational agility for in-store shopping situations (Section 3). For this purpose, the concept of knowledge-based bundling was formulated and exemplified with applicable knowledge from prior research on smart products (Section 4). Then, an implementation of the MRA concept is described that helps customers to buy bundles as they provide dynamic product information of smart products (Section 5). Finally, we conducted a lab experiment to evaluate dynamic product information provided by MRA for bundle purchases according to their user acceptance (Section 6). In summary, we aim for relevant contributions of rigorously evaluated MRA for bundling scenarios based on smart products, which hopefully pave the ground for further research as described in the last section. An overview of the IS research framework of this paper is shown in Figure 1.

\begin{tabular}{|c|c|}
\hline \multicolumn{2}{|c|}{$\begin{array}{c}\text { Organizations } \\
\text { Bundling Strategy (Section 2) } \\
\text { Technology } \\
\text { Smart Products (Section 2) } \\
\text { Mobile Recommendation Agents (Section 2) }\end{array}$} \\
\hline Relevance & $\begin{array}{l}\text { Business Needs } \\
\text { (Section 3) }\end{array}$ \\
\hline \multicolumn{2}{|c|}{$\begin{array}{c}\text { Develop/Build } \\
\text { Knowledge-based Bundling of Smart Products (Section 4) } \\
\text { Mobile Recommendation Agent for Bundling Purchases (Section 5) } \\
\text { Justify/Evaluate } \\
\text { Lab Experiment on Bundle Purchases, } n=37 \text { (Section 6) }\end{array}$} \\
\hline Rigor & $\begin{array}{l}\text { Applicable } \\
\text { Knowledge }\end{array}$ \\
\hline $\begin{array}{r}\text { Sme } \\
\text { Se } \\
\text { Tip }\end{array}$ & $\begin{array}{l}\text { 3ase } \\
\text { ns } \\
\text { (St (SPDO) (Section 4) } \\
\text { (SWRL) (Section 4) } \\
\text { t Products (Section 5) } \\
\text { ies } \\
\text { t-Test (Section 6) }\end{array}$ \\
\hline
\end{tabular}

Figure 1. Underlying IS research framework of this article according to Hevner et al. [11, p. 80]

\section{Related Work}

Physical products increasingly incorporate information technology that facilitates the differentiation of products in competitive markets [3]. For instance, RFID-based Electronic Product Codes (EPC) attached to products allow the retrieval of associated product information that can be used for differentiation [12]. Products that actively use information services for adaptations to situations, users and other products are denoted as smart products [13, 14]. They are claimed to be situated, personalized, adaptive, pro-active, business-aware and networkcapable [4]. Self-describing data models that use semantic product descriptions such as the Smart Product Description Object (SPDO) [4] allow the implementation of the six characteristics described above. Correspondingly, by using semantic data models, the integration of standardized (BMECat, eCl@ss, EPC global formats) and non-standardized product data is also accomplished with less effort through mapping mechanisms compared to extensive migrations of existing product data [12].

The potential of new business processes and services for smart products (e.g. products may be able to sell themselves) is suggested to be very high [3]. In such, price discrimination strategies as proposed by Pigou [7] can be implemented by attaching the corresponding information to smart products. Price discrimination is present "when two or more similar goods are sold at prices that are in different ratios to marginal costs" [15]. There exist several pricing implementation forms that can be assigned to the three degrees of price discrimination [7] as listed in Table 1 $[16$, p. 123]. Here, we focus on bundling strategies, as they are subject to a broad range of research and suit well to the concept of smart products that are businessaware and network capable. Stigler [17] and Adams and Yellen [8] describe economic advantages of bundling strategies, whereas Stremersch and Tellis classify bundling strategies based on their focus (price or product bundling) and their form (pure bundling, mixed bundling or unbundling) [18]. Matutes and Regibeau [10] investigate on the compatibility and the bundling of complementary products. Several mixedinteger and probabilistic models for the pricing of product bundles are proposed as well [19-21].

On the other side, Mobile Commerce (MCommerce) is starting to become a promising and lucrative growth market [22] as M-Commerce allows Electronic Commerce activities on mobile devices such as a mobile phone or PDA [23]. Therefore, product recommendation services will be not only available within online shopping situations where they have recently gained major interest in the Information Systems research community $[2,24]$ but also in bricks- 
and-mortar stores on mobile devices. Bo and Benbasat define integrated sets of recommendation services as "software agents that elicit the interest or preferences of individual users for products either explicitly or implicitly, and make recommendations accordingly" [2 p. 137]. Several studies showed that recommendation agents (RA) provide value-added services that help to reduce customer's information overload in shopping situations and reduce search complexity [25, 26], improve decision quality [27], and trust in decisions $[28,29]$. RA based on online shopbots are developed recently for bundle purchases [30].

MRA are subsumed under the class of RA with a specialization on in-store situations [31]. Purchase decisions within in-store shopping situations depend on product information that can be "imperfect for a number of reasons, such as the proliferation of competing brands, the difficulties of exhaustive search or sampling, biases in product evaluation, constant product innovation or consumer mobility" [32].

Hence, MRA research specializes on recommendation services by the consideration of spatial anchoring, stronger emphasis of physical and social contexts, and limitations given by smaller technical devices. Recent studies showed that the importance of efficient information coding systems help to reduce cognitive load [31]. It is shown that benefits, i.e. time convenience, user control and service compatibility, and costs, i.e. risk and cognitive effort, affect the intention to use mobile recommendation services [33]. In addition, it is found that both perceived ease of use and relative advantage (in comparison to static product information, e.g. printed product labels) predict the behavioral intention to use MRAs for bundle purchases [6].

Table 1. Implementation forms assigned to the three degrees of price discrimination according to [16, p. 123].

\section{Price Discrimination}

\begin{tabular}{llc} 
First-degree & Second-degree & Third-degree \\
\hline - Auctions & $\bullet$ Bundling & $\bullet$ Individual- \\
- Negotiations & - Quantity-based & related \\
& discrimination & discrimination \\
& - Performance- & - Region-based \\
& based & discrimination \\
& discrimination & - Time-based \\
& - Group-based & discrimination \\
& discrimination &
\end{tabular}

\section{Motivation}

According to Stigler [17] and Adams and Yellen [8], bundling activities allow retailers and producers to reduce transaction costs, production costs and information costs and at the same to skim consumer surplus which varies due to different reservation prices of the buyers.

Up until now, bundles are mostly offered on printed product labels in bricks-and-mortar stores, which is quite static in its process (e.g. exactly two or more products are labelled as a bundle) and requires manual effort for labelling each bundle.

By contrast, in combination with smart products and MRAs, bundling strategies are more dynamic and enable operational agility that "reflects the ability of firms' business processes to accomplish speed, accuracy, and cost economy in the exploitation of opportunities for innovation and competitive action" [34, p. 245]. Furthermore, a product bundling scenario based on smart products and MRAs would improve operational agility as it allows retailers to "reduce information asymmetries between buyers and sellers through rapid and up-to-date supply of comprehensive information, often through the use of electronic distribution channels" [34, p. 246].

Here, smart products together with MRA implement those electronic distribution channels and improve the availability and quality of information on bundles that are required for in-store purchase decisions [1]. For instance, MRA provide customers with dynamic product information that support the customer in finding complementary products on demand. Hence, MRA enable customer-product communication for bundle purchases dynamically and directly at the point of sale and thus define a clear and relevant business need. To understand the underlying framework of this new kind of bundling technology we first introduce the concept of knowledge-based bundling that relies on smart products and their semantic data model SPDO before our MRA implementation is described and evaluated.

\section{Knowledge-based Bundling}

\subsection{Definition}

On the one hand, Stremersch and Tellis [18] distinguish between product bundling that is defined as ,the integration and sale of two or more separate products or services at any price“" (p. 57), and price bundling that is the "sale of two or more separate products in a package at a discount, without any integration of the products" (p. 56). In contrast to product bundling, price bundling does therefore "not 
create added value to customers [such as a seamless interaction of a home cinema system, author's note], and thus a discount must be offered to motivate at least some customers to buy the bundle" (ibid.). In addition, they classify bundling into a pure bundling strategy "in which a firm sells only the bundle and not (all) the products separately" (p. 57) and a mixed bundling strategy "in which a firm sells both the bundle and all the separate products in the bundle separately" (ibid.). Stremersch and Tellis also mention unbundling strategies in which products are only sold separately. Hence, the last form of bundling is neglected, as it is not within the scope of this article.

On the other hand, smart products are businessaware and network capable and therefore incorporate detailed knowledge of their own product information and at the same time recognize their context through embedded information technology. As a result, smart products are aware of both (1) their own knowledge such as the name of the product or the recommended sales price and (2) their contextual knowledge such as other products or additional information on special offers that are available from the retailer's data repository. All in all, the own and contextual knowledge of smart products can be used for all bundling strategies as described above: product and price bundling as well as pure and mixed bundling strategies. Hence, we define knowledge-based bundling as the sale of two or more separate products at any price based upon the product's own and contextual knowledge.

Figure 2 illustrates knowledge-based bundling of smart products in the form of a block diagram. Accordingly, a smart product $\mathrm{A}$ is able to bundle with another product B due to its own and contextual knowledge. This knowledge provides detailed product specifications, which can be used to identify only those bundles consisting of compatible products. For instance, a consumer may ask a digital camera for compatible accessories such as memory cards. The digital camera knows all compatible accessories through its context and recommends them to the consumer in the form of a product bundling strategy as both products are integrated by means of technical compatibility [10]. The price of the bundle is finally parameterized by the knowledge of both smart products, e.g. a recommended sales price of the producer, and by their contextual knowledge, e.g. a promotion week of a retailer with special offers on specific product bundles.

The logic behind this bundling process is described by semantic product descriptions and rules that define the correct composition of product bundles. These rules may be based on strategic considerations, e.g. special offers or contracts between producers, or technical considerations, e.g. interface compatibilities. A data model for semantic product descriptions and a rule that defines bundles are described in the following two subsections 3.2 and 3.3, respectively.

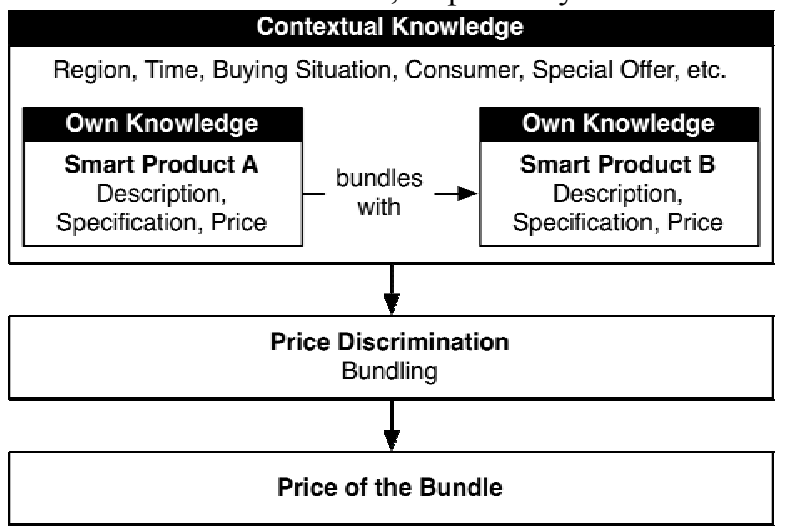

Figure 2. Knowledge-based bundling of smart products based on the product's own and contextual knowledge.

\subsection{Data Model for Knowledge-based Bundling}

Because of the complexity of products in general we assume that different product categories have different requirements for describing product attributes in more or less detail and variety. As typical for webbased systems we adopt an extensible data model called Smart Product Description Object (SPDO) that leads to variable semantics based on formal ontologies. The SPDO model consists of five facets [5, 13]: (1) product description, (2) presentation description, (3) community description, (4) business description, and (5) trust \& security description. In our SPDO reference implementation we use the foundational ontologies DOLCE-Ultralight that is a leightweight version of DOLCE [35] and DnS [36] with domain-specific core conceptualizations for semantic descriptions of SPDO instantiations. In DOLCE/DnS, a SPDO instantiation is an information object realization that explicates a conceptualization.

SPDO instantiations are processed by the Tip 'n Tell middleware [5]. A request on a product in focus is sent via a SPARQL-based request protocol to a SPDO broker that manages product information by the semantic representation format OWL. This broker collects requested product information from web services that are referenced by the product ID in the product description facet of a SPDO. The SPDO broker integrates product information from different sources into SPDO representations and sends it to a 
dynamic product interface such as the MRA (see the following section) in focus for communication with users. In the following we describe how SPDO models are used for reasoning purposes. This is exemplified by an in-store shopping situation that describes a product bundling scenario with mobile navigation units and compatible accessories based on price considerations.

\subsection{A Bundling Shopping Example}

In this example, a smart mobile navigation unit is asked by a customer to suggest accessories within a bricks-and-mortar store. The retailer has defined a rule that allows products to be suggested based on their price level without belonging to the same product category. Only those products are therefore suggested to be bundled with a product $\mathrm{A}$ that belong to the same price level but to different product categories in comparison to product A. For ease of presentation, we define only two categories (Mobile Navigation Unit and Accessory) and two price levels, above and below the average price of all products within one category.

By using the Semantic Web Rules Language (SWRL), the rule in Listing 1 marks all SPDO instantiations of products with the property low price level that belong to the category Mobile Navigation Unit (line 6) by comparing the product's price (line 9) with the calculated average price of the corresponding category (line 12).

Because the SWRL currently not supports subqueries, several steps are necessary to get the result sets that are used for product bundling. These steps consist of results of one or more rules that are used to fill the wild-cards of the next rules. Therefore, the category (e.g., Mobile Navigation Unit) and average price (e.g., 305€) in Listing 1 are results from other rules. The single steps to mark all the products for bundling are as follows:

1. Find all products that are currently in the system and which provide a product category and price information.

2. Calculate the average price of all products within one category
3. Mark each product with high or low price levels by comparing the product's price the category's mean price (see Listing 1 for the category Mobile Navigation Unit).

4. Mark each two products from different categories as bundle if they belong to the same price level.

Then, by reasoning over all SPDO instantiations, a mobile navigation unit belonging to the low price level suggests only appropriate accessories in such that they represent also low price level products in their category. The MRA that is used for smart product interaction to ask for product bundles is presented in the next section.

\section{MRA Implementation}

In our scenario, smart products are equipped with RFID tags to identify them and to start human product interaction through a MRA. If a product's RFID tag was scanned by a consumer the MRA informs the Tip 'n Tell web service (Java \& Axis2) about this product [5]. The server components manage the semantic data pool using a semantic framework (Jena2) to allow the user to ask questions on the product and its relations to other products like accessories. This information is based on the product information provided by the SPDOs of each product and the results of semantic rules. That rules try to find implicit statements over all products which are derived from the combination of all available SPDO statements.

The communication between the MRA and the server is based on the SOAP web service standard and allows multiple information sessions of different consumers at the same time.

In comparison to our prior MRA implementation [5] the current variant has three major features: First, the former Bluetooth RFID reader pen device (Cathexis IDBlue $^{\mathrm{TM}}$ RFID Pen) is replaced with a Compact Flash reader variant (Socket $6 \mathrm{E}$ ) whereby the reader device and the MRA (HP iPaq Pocket PC) are merged into

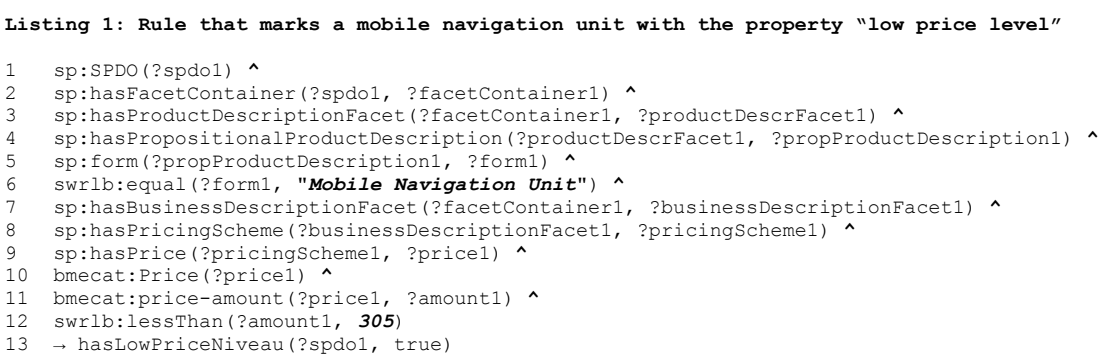


one compact device as shown in Figure 3. As a result of this combination, the pointing gesture at a smart product that is equipped with a RFID tag (ISO15693, HF $13.56 \mathrm{MHz}$, proximity range) eases the user to start interaction with that product.

The second feature refers to the graphical user interface (GUI) as shown in Figure 4. It is optimized to be completely controlled by tapping with the finger. An extra input device like a pen is therefore not required. This feature resulted from the lab experiment about which is reported in the following section.

The third and most important feature is the integration of product bundling capabilities into the MRA. When a user starts a dialogue with a specific product its basic product information and an image is displayed in the top region of the screen. By tapping on the product image an extra window containing a detailed product description is displayed. From the main screen the user has two possibilities:

On the on one hand, the user can ask for alternative products in relation to the main product on the top of the screen by tapping on the button labeled as Alternatives?.

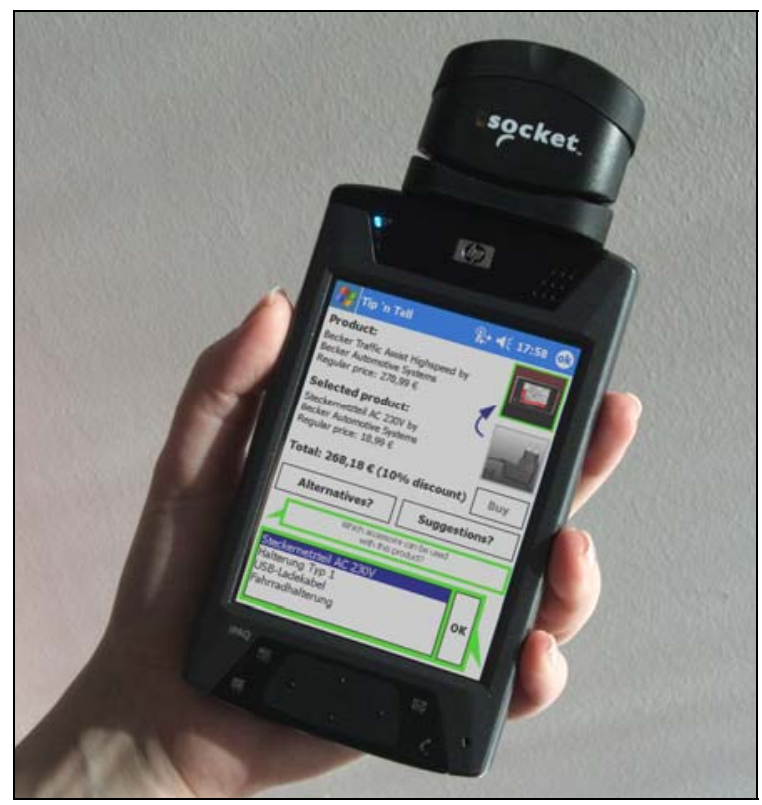

Figure 3. MRA with integrated Socket 6E RFIDReader on the top.

On the other hand, the user can ask for accessories in relation to the main product at the top of the screen by tapping on the other button labeled as Suggestions?. This question was described in our bundling shopping example in Section 3.3.

The answers for both questions that are directed at the main product are displayed in the box at the bottom of the screen. If the user taps on one product that came up as an answer, the corresponding product information is displayed below the main product as well. The blue arrow enables the user to switch the both products. This allows the user to change the main product within the buying decision process and to start a new dialog.

Additionally, the user is shown the total price and discount, when having two products selected that are marked as a bundle. Depending on the price level or other factors (e.g. special offers), the producer or retailer may discount the product bundle dynamically.

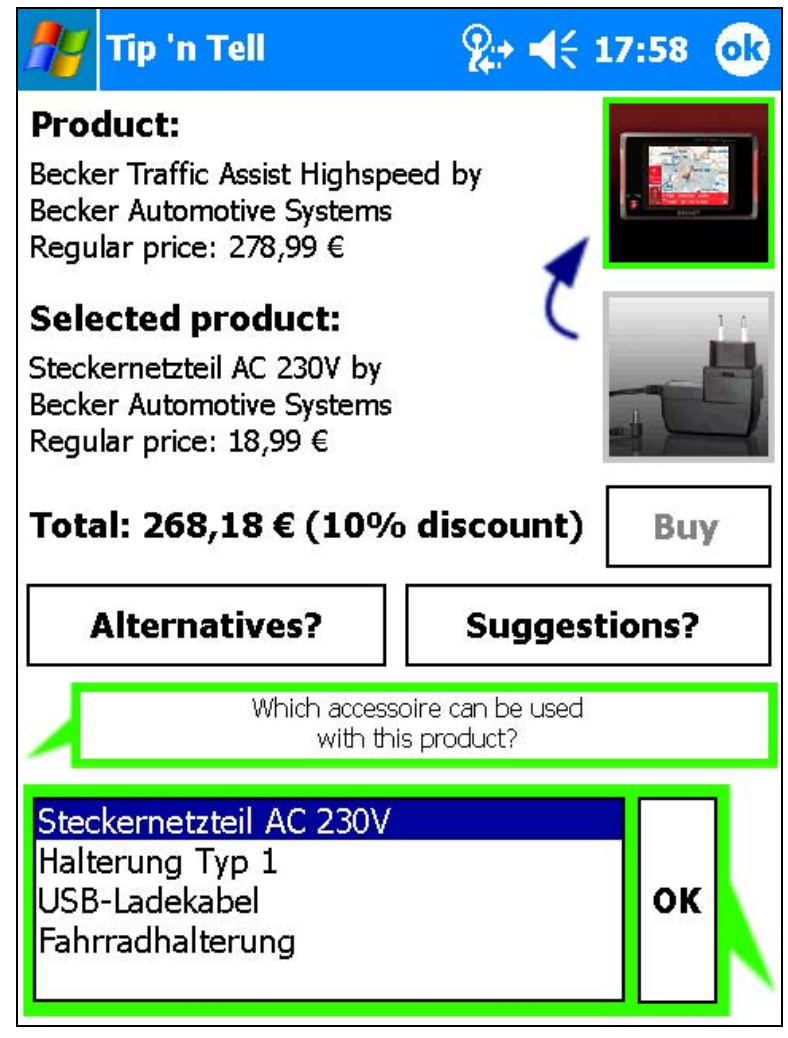

Figure 4. Screenshot of the MRA that suggests four complementary accessories to the mobile navigation unit at the top

\section{Evaluation}




\subsection{Perceived Relative Advantage, Ease of Use, and User Acceptance}

Three theoretical constructs are of interest within in-store purchase situations for the evaluation of MRAs that provide dynamic product information for bundle purchases. The first is perceived relative advantage, which is defined as the degree "to which an innovation is perceived as better than the idea it supercedes" [37, p. 476]. In our context, dynamic product information provided by the MRA represents the innovation that adapts to the consumer's needs for bundle purchase decisions and thus supersedes static product information as it can be found traditionally in brick-and-mortar stores.

Perceived ease of use is the second construct used for this evaluation. It refers to the degree "to which a person believes that using a particular system would be free of effort" [38, p. 320]. Here, our MRA supports the consumer with a dialog-based system, which is used to ask for product information on demand. The consumer is therefore able to choose information, which she perceives as relevant for her purchase decision. In particular, ease of use becomes obvious, if the MRA recommends only those products that are compatible with each other in case of a bundle purchase.

Furthermore, we are interested in the user acceptance according to the dynamic product information provided by the MRA. Hence, the behavioral intention to use dynamic product information for bundle purchases on a MRA within the next three years was evaluated.

Finally, we are also concerned in the actual usage and handling of the MRA. Hence, we wanted to ask for feedback directly within usage situations to gather qualitative data for upcoming performance and design enhancements.

\subsection{Method}

In order to evaluate the MRA for bundle purchases, we conducted a lab experiment. According to the experimental setting, we choose a product bundle strategy in combination with a pure bundling strategy as our MRAs was developed to help customer in finding integrated product bundles based on their compatibility. Therefore, subjects were allowed to buy only a bundle consisting of two complementary products: one mobile navigation unit and one accessory. There were four navigation units and eight accessories available for selection. The only precondition for this selection task was the compatibility of the two products as each of them supported one or more standards (see Appendix 1 of [6]). All subjects had to select the products in two experimental settings, (1) shopping with the help of dynamic product information that were provided by our MRA and (2) shopping without such assistance. In addition to the first setting, subjects were given instructions on how to use the MRA. As one of its key features, the MRA suggested only those accessories that were compatible to a particular mobile navigation unit a subject chose. If subjects had any problems with the MRA, they were requested to provide directly feedback, which was recorded in writing for qualitative analysis. By contrast, the second experimental setting provided subjects with printed labels containing all standards that a product supported.

In the second part of the experiment, subjects were given a questionnaire according to the constructs relative advantage (six items), ease of use (seven items) and the behavioral intention to use dynamic product information (two items). Corresponding items were taken from [6]. Consistent with prior research on the adoption of IT, all items were based on seven-point Likert scales, ranging from extremely disagree to extremely agree. The questionnaire was also used to collect demographic data and to ask for the length and comprehensibility of the experiment.

\subsection{Results and Discussion}

Thirty male and seven female students of Furtwangen University participated in the lab experiment. Their age ranged from 20 to $24(\mathrm{~N}=23)$, 25 to $29(\mathrm{~N}=13)$ and 30 to $34(\mathrm{~N}=1)$. Overall, the instructions of the experiment and the questionnaire were quite understandable and acceptable on its length. Cronbach's alpha reliability yielded viable .91 and .79 for the perceived constructs relative advantage and ease of use, respectively. Alpha for the intention to use construct resulted in .80 .

Maass and Kowatsch [6] found that relative advantage and ease of use predict the behavioral intention to use dynamic product information for bundle purchases. In contrast to the latter, we show that the mean value of the ratings was significantly below or above the neutral value of 3. For this purpose, we applied t-tests for one sample. According to the figures of Table 2Table 2, dynamic product information provided by the MRA exceeds static product information for buying a product bundle significantly. Dynamic product information was also easy to use for all of the subjects on average. And finally, subjects would also use dynamic product information to buy a product bundle in the next three 
years. Therefore, promising acceptance rates for MRA can be derived for in-store shopping situations, in which product bundles are bought.

Table 2. Results of one-sample t-tests for the perceived constructs relative advantage (PRA), ease of use (PEU) and intention to use (IU); $n=37$; neutral test value $=3$

\begin{tabular}{l|ccc} 
Construct & Mean & SD & p \\
\hline PRA & 4.43 & 1.04 & $<.001$ \\
PEU & 4.63 & 0.75 & $<.001$ \\
IU & 4.30 & 1.33 & $<.001$
\end{tabular}

By observing and interviewing the participants that were interacting with the MRA, we suggest the following two guidelines that were partially integrated into the MRA after the experiment:

- Optimize latency: If subjects perceive the responses of MRAs as being too long due to a temporal loss of web service performance or other communication problems, trepidation comes up. Here, a caching mechanism may optimize the interaction with the MRA. But caching mechanisms have to be implemented carefully, because real-time updates on product's prices or other business-related attributes have to be considered if producers or retailers start special offers or marketing campaigns on demand.

- Clean up the GUI: The GUI of the MRA was first overloaded by to many buttons and lists that were used to ask detailed questions, e.g. to ask for the product's producer. This complex GUI was time-consuming to learn and participants were hindered to choose appropriate product bundles quickly. As one solution, only task-oriented buttons such as one suggestion button for product bundling queries should be shown to the consumer as described in the last section. Otherwise, questions could also be created word by word if a semantic language processing tool is available and supports the consumer with the question building process by providing only few interaction buttons.

\section{Conclusion and Future Research}

In this article we introduced knowledge-based bundling that is based upon smart products and MRA. This new kind of interaction between a consumer and a product together with M-Business technologies will rapidly change brick-and-mortar stores and purchase situations as they can improve the operational agility of retailers. The SPDO data model was used to exemplify knowledge-based bundling with a set of corresponding rules. Then, we presented our MRA implementation that facilitates the bundling of smart products for end customers. Results of a lab experiment were then discussed and led to promising user acceptance rates in product bundling scenarios. In addition, two guidelines were identified to enhance the performance and the design of MRA, respectively.

In our future work, we evaluate knowledge-based bundling in other bundling scenarios based upon price and mixed bundling strategies. We also investigate on the integration of dynamic pricing models for mobile business applications into our MRA through the connection of our Tip ' $n$ Tell middleware with corresponding web services. In particular, dynamic pricing models that belong to first-degree price discrimination such as individual negotiations or auctions are here of interest, because smart products are claimed to adapt to their buyers and therefore play out their strengths. Additionally, the MRA will be extended by caching mechanisms and natural language processing support that allows costumers to ask smart products sophisticated questions. Furthermore, the MRA interface will be adapted to other mobile devices such as mobile phones to examine the flexibility of the semantic approach of the data model. And finally, more lab experiments and field studies will be conducted to obtain new requirements for the next build-and-evaluate loop such that smart products and MRA will be adopted by retailers and their costumers not only for bundle purchases to bring M-Business one step further.

\section{References}

[1] Krotov, V. and Junglas, I., "Mobile Technology as an Enabler of Organizational Agility," in International Conference on Mobile Business (ICMB'06) Copenhagen, Denmark, 2006.

[2] Bo, X. and Benbasat, I., "E-Commerce Product Recommendation Agents: Use, Characteristics, and Impact," MIS Quarterly (31:1), 2007, pp. 137-209.

[3] Konana, P. and Ray, G., "Physical Product Reengineering with Embedded Information Technology," Communications of the ACM (46:1), 2007, pp. 72-78.

[4] Maass, W., Filler, A., and Janzen, S., "Reasoning on Smart Products in Consumer Good Domains," in Mühlhäuser, M., Ferscha, A., and Aitenbichler, E., Eds. Constructing Ambient Intelligence (CCIS 11), Heidelberg, Germany: Springer, 2008. 
[5] Maass, W. and Filler, A., "Towards an Infrastructure for Semantically Annotated Physical Products," in Hochberger, C. and Liskowsky, R., Eds., Informatik 2006, Lecture Notes in Informatics, Berlin, Germany: Springer, 2006, pp. 544549 .

[6] Maass, W. and Kowatsch, T., "Adoption of Dynamic Product Information: An Empirical Investigation of Supporting Purchase Decisions on Product Bundles," in 16th European Conference on Information Systems (ECIS'08) Galway, Ireland, 2008.

[7] Pigou, A. C., The Economics of welfare. London: Macmillan, 1920.

[8] Adams, W. J. and Yellen, J. L., "Commodity bundling and the burden of monopoly," Quarterly Journal of Economics (90:3), 1976, pp. 475-498.

[9] Elmaghraby, W. and Keskinocak, P., "Dynamic Pricing in the Presence of Inventory Considerations: Research Overview, Current Practices, and Future Directions," Management Science (49:10), 2003, pp. 1287-1309.

[10] Matutes, C. and Regibeau, P., "Compatibility and bundling of complementary goods in a duopoly," The Journal of Industrial Economics (40:1), 1992, pp. 37-54.

[11] Hevner, A. R., March, S. T., Park, J., and Ram, S., "Design Science in Information Systems Research," MIS Quarterly (28:1), 2004, pp. 75-105.

[12] Maass, W. and Lampe, M., "Integration of Standardized and Non-Standardized Product Data," in Koschke, R. and Rödiger, K.-H., Eds., Informatik 2007, Lecture Notes in Informatics, Berlin, Germany: Springer, pp.141-164, 2007.

[13] Maass, W. and Janzen, S., "Dynamic Product Interfaces: A Key Element for Ambient Shopping Environments," in Proc. of the 20th Bled eConference, Bled, Slovenia, 2007.

[14] Aitenbichler, E., Lyardet, F., Austaller, G., Kangasharju, J., and Mühlhäuser, M., "Engineering intuitive and self-explanatory smart products," in Proc. of the 2007 ACM Symposium on Applied Computing, Seoul, Korea, 2007, pp. 1632 - 1637.

[15] Stigler, G. J., The Theory of Price. New York, NY, USA: Macmillan, 1987.

[16] Stahl, F., Paid Content. Wiesbaden, Germany: Deutscher Universitäts-Verlag, 2005.

[17] Stigler, G. J., "United States v. Loew's Inc.: A Note on Block-Booking," in The Supreme Court Review (1963). Chicago, USA: The University of Chicago Press, 1963, pp. 152-157.
[18] Stremersch, S. and Tellis, G. J., "Strategic Bundling of Products and Prices: A New Synthesis for Marketing," Journal of Marketing (66), 2002, pp. 55-71.

[19] Hanson, W. and Martin, R. K., "Optimal bundle pricing," Management Science (36:2), 1990, pp. 155 - 174.

[20] Venkatesh, R. and Mahajan, V., "A Probabilistic Approach to Pricing a Bundle of Products or Services," Journal of Marketing Research (30:4), 1993, pp. 494-508.

[21] Bitran, G. R. and Ferrer, J.-C., "On Pricing and Composition of Bundles," Production and Operations Management (16:1), 2007, pp. 93-108.

[22] Kim, H.-W., Chan, H. C., and Gupta, S., "Value-based Adoption of Mobile Internet: An empirical investigation," Decision Support Systems (43:1), 2007, pp. 111-126.

[23] Lee, Y. E. and Benbasat, I., "Interface Design: for Mobile Commerce," Communications of the ACM (46:12), 2003, pp. 48-52.

[24] Ting-Peng, L., Hung-Jen, L., and Yi-Cheng, K., "Personalized Content Recommendation and User Satisfaction: Theoretical Synthesis and Empirical Findings," Journal of Management Information Systems, (23:3), 2007, pp. 45-70.

[25] Häubl, G. and Trifts, V., "Consumer Decision Making in Online Shopping Environments: The Effects of Interactive Decision Aids," Marketing Science (19:1), 2000, pp. 4-21.

[26] Todd, P., "Evaluating the Impact of DSS, Cognitive Effort, and Incentives on Strategy Selection," Information Systems Research (10:4), 1999, pp. 356-374.

[27] Pereira, R. E., "Influence of Query-Based Decision Aids on Consumer Decision Making in Electronic Commerce," Information Resources Management Journal (14:1), 2001, pp. 31-48.

[28] Gregor, S. and Benbasat, I., "Explanations From Intelligent Systems: Theoretical Foundations and Implications for Practice," MIS Quarterly (23:4), 1999, pp. 497-530.

[29] Komiak, S. Y. X. and Benbasat, I., "The Effects of Personalization and Familiarity on Trust and Adoption of Recommendation Agents," MIS Quarterly (30:4), 2006, pp. 941-960.

[30] Garfinkel, R., Gopal, R., Tripathi, A., and Yin, F., "Design of a shopbot and recommender system for bundle purchases," Decision Support Systems (42:3), 2006, pp. 1974-1986. 
[31] Van der Heijden, H., "Mobile decision support for instore purchase decisions," Decision Support Systems (42:2), 2006, pp. 656-663.

[32] Stahl, F. and Freudenschuss, M., "Mobile business through RFID technology," in Proc. of the 12th Americas Conference on Information Systems (AMCIS'06), Acapulco, México, 2006.

[33] Kleijnen, M., de Ruyter, K., and Wetzels, M., "An assessment of value creation in mobile service delivery and the moderating role of time consciousness," Journal of Retailing, (83:1), 2007, pp. 33-46.

[34] Sambamurthy, V., Bharadwaj, A., and Grover, V., "Shaping Agility through Digital Options: Reconceptualizing the Role of Information Technology in Contemporary Firms," MIS Quarterly (27:2), 2003, pp. 237-263.

[35] Masolo, C., Borgo, S., Guarino, N., and Oltramari, A., "The WonderWeb Library of Foundational Ontologies," WonderWeb D17, 2003.

[36] Gangemi, A., Borgo, S., Catenacci, C., and Lehmann, J., "Task Taxonomies for Knowledge Content," METOKIS Deliverable D07, 2004.

[37] Rogers, E. M., Diffusion of Innovations, 5 ed., New York, USA: Free Press, 2003.

[38] Davis, F. D., "Perceived Usefulness, Perceived Ease of Use, and User Acceptance of Information Technology," MIS Quarterly (13), 1989, pp. 319-339. 